Goldschmidt 2021 Abstract

https://doi.org/10.7185/gold2021.8098

\section{Tracking the evolution of a submarine arc-hosted hydrothermal system through the deportment of phosphorous and rare-earth elements}

\author{
TOBIAS W HÖFIG ${ }^{1}$, ANDREW V MOTT ${ }^{1}$, BRENT V \\ MILLER $^{1}$, LAWRENCE K HORKLEY ${ }^{2}$, CHAO ZHANG ${ }^{3}$ \\ AND DAVID W PEATE ${ }^{2}$
}

${ }^{1}$ Texas A\&M University

${ }^{2}$ University of Iowa

${ }^{3}$ Northwest University

Presenting Author: hoefig@iodp.tamu.edu

The subseafloor structure of an arc-hosted hydrothermal system was drilled by IODP Expedition 376 at Brothers volcano. Recovered cores contain accessory phosphates that offer clues to its evolution. Caldera wall (Hole U1530A) alteration mineral assemblages indicate an older, inactive, low-pH, magmatically influenced hydrothermal system ( $\geq 225 \mathrm{~m}$ below seafloor [mbsf]) that is partially overprinted by a seawater-dominated, medium$\mathrm{pH}$, higher temperature hydrothermal system forming a nearseafloor stockwork zone [1]. Additionally, a younger cone (Hole U1528D) hosts an active, low-pH, magmatic fluid-driven hydrothermal system akin to the deeper caldera wall subseafloor section.

The composition of phosphate minerals changes from magmatic to hydrothermal mineral formation stages. The sole primary (magmatic) phosphate contained in fresh volcanic rocks (Holes U1529B, U1531E) is euhedral fluor-chlorapatite found in the matrix or as inclusions in clinopyroxene and plagioclase phenocrysts. Secondary (metasomatic) phosphate mineralization, however, is represented by a variety of different phases. Interstitial anhedral fluorapatite is associated with late-stage seawater-derived alteration minerals. This secondary apatite often exists along with disseminated, relic florencite $\left[\mathrm{LREEAl}_{3}\left(\mathrm{PO}_{4}\right)_{2}(\mathrm{OH})_{6}\right]$ crystals. The latter can also be found in vugs that occasionally resemble the shape of apatite crystals. Within the stockwork zone $(\leq 20$ mbsf $)$, magnesium metasomatism has led to formation of Mg-enriched fluorchlorapatite and fluorine-rich $\mathrm{Mg}$-hydroxyphosphates. At the volcanic cone, magmatic apatite has been replaced by a compositionally complex paragenesis of euhedral aluminumphosphate-sulfate (APS) minerals. APS crystals show oscillatory zoning manifested by alternating LREE-phosphorous-enriched and -depleted growth shells. Sulfur enrichment occurs at the expense of phosphorous depletion.

This suggests that hydrothermal apatite formation was prevented by the initially magmatically influenced fluid circulation due to highly acidic conditions that solely favored APS minerals as the only P-bearing precipitates. Among these, LREE-bearing, P-rich APS phases may have formed during low$\mathrm{S}$ and/or high-P pulses with decreased chloride activity, as lower chlorine contents coincide with enrichment of REE in compositionally zoned APS crystals. Their seawater-driven alteration may have formed a significant phosphorous source to enable the precipitation of late-stage hydrothermal apatite. The latter even shows rare minute $(<2 \mu \mathrm{m})$ inclusions of REE-phosphates monazite (LREE) and xenotime (HREE) likely resulting from dissolution-precipitation reactions.

[1] de Ronde et al. (2019), Geology 47, 762-766. 